\title{
Tras el grito
}

\section{Carlos Antonio Villa Guzmán}

En nuestra época, la humanidad enfrenta una desafiante encrucijada cuya historia comenzó hace unos cien años, al ser declarada la guerra contra las drogas, una de las mayores injusticias que se hayan cometido y también una de las menos analizadas.

Tras el Grito, es un libro escrito por el periodista británico Johann Hari, en el cual narra el periplo que experimentó al explorar en las cavernas más recónditas que forman parte del sub mundo de las drogas, de donde obtuvo un material prolijo en detalles que hacen emerger de estas profundidades lo que nadie suponía o imaginaba. Casi todo lo que se nos ha descrito o señalado sobre este complejo entramado, no corresponde a lo que es en realidad.

Cimentado sobre objetivos distintos a los que se les dio difusión, como parte de una estrategia montada para justificar una acción supuestamente justa y además necesaria para sanear la sociedad, según algunos ya bastante afectada por causa de lo que consideraron el flagelo del comercio del alcohol, lo cual llevó a su prohibición en Estados Unidos entre 1920 y 1933, el combate a la producción, tráfico y consumo de drogas obedece a ciertas lógicas que el autor devela en un relato que envuelve a los lectores desde las primeras páginas. El corpus del libro apela constantemente a varios campos del Derecho, entre otras disciplinas, al poner ante nuestra mirada aquello relacionado con la actualidad, peligrosamente atravesada por esta problemática y que subyace oculto o mimetizado, de tal forma que pasa por auténtico y formalmente dentro de la ley.

Se trata de un ensayo sorprendentemente realista, apegado a hechos que tuvieron lugar en espacios y tiempos distintos, pero fuertemente ligados por la rigurosa crueldad con la que se desenvuelven los días de quienes forman multitudes en esta trama de persecución, adicción, lucha, acoso, castigo, locura, entre otras consecuencias de fuerte impacto social. El autor nos demuestra que los laberintos de la dependencia y el consecuente tráfico, se hallan sujetos a las

Doctor Investigador en Ciencias Políticas. Universidad de Guadalajara. 
redes de quienes persiguen a la vez que se benefician de estos subterráneos, de donde surgen fortunas equiparables a las que genera la industria del petróleo. Hay, por tanto, actores visibles e invisibles, que a su vez están dentro y fuera de la legalidad. Son ellos los que juegan esos roles que forman el espejismo que hace creer que se libra una auténtica guerra, pero es mucho más que eso.

Este trabajo es el resultado de una investigación que llevó tres años y más de 50 mil kilómetros de recorridos en los cuales fueron tomadas, como piezas de un entramado global, las experiencias de algunos personajes elegidos como ejemplo para entender qué es realmente esta guerra, a qué intereses responde y cuales han sido y serán sus consecuencias en un futuro cercano.

¿Por qué se sienten y son perseguidos, acosados, señalados, segregados y hasta explotados quienes practican algún tipo de adicción o trafican con determinada sustancia considerada como droga? ¿Cuándo y por qué se origina todo esto y cuáles son las justificaciones que asumen los gobiernos que han emprendido y otros que en cierta forma pierden esta guerra? ¿Cuáles han sido los costos que ha representado en términos del daño social y el gasto económico? ¿Cuándo y cómo tendrá fin? ¿Por qué puede haber víctimas con características tan distintas en cuanto a su formación, actividad, nivel social, su estado económico u otros? ¿Cómo fue que entre ellas hubiera talentos tan destacados como los que tenía la cantante norteamericana Billie Holiday, entre muchos otros artistas?

El autor señala que la prohibición "crea un sistema en el que la violencia más demente y sádica tiene una lógica funcional y sensata. Porque es necesaria. Porque tiene una recompensa".

Hari, hilvana esta narración con episodios que vivieron personajes reales, a quienes da voz para que hablen de sus propias historias. Propone, a través del recorrido de cerca de cuatrocientas páginas, que sea discutido con otra racionalidad el tema de la legalización de las drogas, a la vez que trata de luchar, por medio de lo que ha investigado y publicado, para que se ponga final a este conflicto que no deja sino una trágica e indescriptible secuela de amargura, sobre todo en algunos países donde se pierden diariamente las vidas de personas inocentes. "Cualquier individuo puede iniciar la lucha, y cualquier país del mundo romper la cadena y empezar el proceso de legalización de las drogas. Si Uruguay -una nación pequeña de tres millones de habitantes a cuyo frente se encuentra un disidente 
anarquista- es lo bastante osada, ¿por qué no Gran Bretaña o Australia o cualquier otra nación?"

El periodista Johann Hari ha escrito para diarios como The New York Times, Los Ángeles Times, The Guardian, Le Monde, Slate, The New Republic $y$ The Nation, entre otros. Además de ser columnista en The Independent durante nueve años, fue nombrado en dos ocasiones el periodista del año por Amnistía Internacional en el Reino Unido. También ha sido nombrado Cultural Commentador of the Year por Editorial Intelligence Awards y Gay Journalist of the Year, por Stonewall. Actualmente reside en Londres.

Este libro publicado en 2015, es de lectura necesaria tanto para expertos como para quienes se interesan por conocer más en profundidad lo que significa y la trascendencia que tiene en múltiples esferas este fenómeno. Es recomendable para estudiantes de cualquier área social, en especial aquellos que se forman en alguna especialidad de las ciencias jurídicas, a la vez que su lectura también se hace imprescindible para quienes desean entender, de una forma más objetiva, este complejo mundo relacionado con drogas y las implicaciones que trae consigo combatirlas con fuerzas armadas, asimismo reflexionar sobre las consecuencias que conlleva criminalizar el uso de ellas con leyes punitivas, sin mencionar el profundo estigma social que puede llegar a tener un consumidor. Tampoco se pueden soslayar los múltiples casos de suicidios ocasionados por un inadecuado manejo de la adicción. ¿Es este un asunto de legalidad solamente o también corresponde a las áreas de salud pública?

Lecturas como esta son necesarias para encontrar salidas inteligentes, que sirvan al propósito de trascender, por medio de la justicia, esta etapa dolorosa y oscura que atraviesan las sociedades contemporáneas.

\section{Bibliografia}

Título: Tras el grito

Autor: Johann Hari

Edición: 2015

$\mathrm{N}^{\circ}$ de páginas: 448 págs.

Editorial: PAIDOS IBERICA

Lengua: CASTELLANO

ISBN: 9788449331251 
